\section{Acidente de trabalho, com material biológico, em profissionais de saúde de hospitais públicos do Distrito Federal, Brasil, 2002/2003}

\author{
Work-related accidents in health care workers \\ from public hospitals in Brasilia, Brazil, 2002/2003
}

\author{
1 Hospital das Forças \\ Armadas, Brasília, Brasil. \\ 2 Faculdade de Ciências \\ da Saúde, Universidade \\ de Brasília, Brasília, Brasil. \\ Correspondência \\ A. Barbosa-Branco \\ Departamento de Saúde \\ Coletiva, Faculdade \\ de Ciências da Saúde, \\ Universidade de Brasília. \\ Campus Universitário \\ Darcy Ribeiro, Brasília, DF \\ 70910-900, Brasil. \\ anadergh@unb.br
}

\begin{abstract}
This study evaluates the knowledge and acceptance of biosafety measures by health care professionals in light of the potential risk of occupational transmission of HIV. The survey assessed 570 health care workers from 6 hospitals, randomly selected from all hospitals in the Federal District (Brasilia), Brazil. The sample corresponds to $15.0 \%$ of the all health professionals in the selected hospitals. These professionals answered a semi-structured questionnaire on knowledge of biosafety and universal precautions, risk of occupational HIV transmission, work-related accidents, use of personal protective equipment (PPE), and acceptance of chemoprophylaxis and HIV testing. The overall accident coefficient was 39.1. Dentists, physicians, and laboratory technicians were those who most frequently suffered such accidents. The accident coefficient was inversely proportional to the hospital capacity. The professionals' knowledge of biosafety concepts and the fact that written norms were displayed in their workstations did not positively affect the work accident coefficient.
\end{abstract}

Biosafety; Acquired Immunodeficiency Syndrome; Health Personnel; Occupational Accidents
Roberta de Betânia Caixeta 1 Anadergh Barbosa-Branco ${ }^{2}$

\section{Introdução}

Estudos sobre acidentes do trabalho com potencial risco de transmissão do vírus da imunodeficiência humana (HIV) em profissionais de saúde têm sido realizados em várias partes do mundo, mais particularmente nos Estados Unidos 1,2. Entretanto, no Brasil, é clara a limitação de estudos epidemiológicos sobre o assunto, além da restrição desses aos profissionais de enfermagem.

O Ministério da Previdência e Assistência Social define acidente de trabalho como o ocorrido pelo exercício do trabalho a serviço da empresa, o qual provoca lesão corporal ou perturbação funcional que cause a morte ou a perda ou redução, permanente ou temporária, da capacidade para o trabalho 3 . Bem antes do advento da síndrome da imunodeficiência adquirida (AIDS), a Lei $n$. 6.367, de 19 de outubro de 1976, já equiparava ao acidente de trabalho a doença proveniente da contaminação acidental do pessoal da área médica 4 .

Os acidentes envolvendo material biológico, freqüentes entre os profissionais de saúde, não se enquadram na definição legal. Contudo, as suas conseqüências, a curto e médio prazo, fazem com que o seu registro junto aos serviços competentes da unidade hospitalar (Medicina do Trabalho, Comissão de Controle de Infecção Hospitalar e outros) seja fundamental. 
O fato da comunicação do acidente de trabalho ser procedimento facultativo é um problema grave, pois, muitas vezes, o acidente não gera nenhuma das situações previstas na definição de acidente de trabalho, nem tampouco, no momento ou muito próximo desse, fica caracterizada a transmissão. Legalmente, esse tipo de acidente não teria comunicação compulsória, realizada apenas quando a doença se desenvolve. Percebe-se claramente, nesse caso, a falta de componente preventivo.

Para garantir os benefícios acidentários dos trabalhadores, grande parte dos hospitais procura estabelecer alguma forma de registro desses acidentes, mas, na prática, há falta de normalização desse procedimento e uma deficiente divulgação junto aos profissionais de saúde. Além disso, é necessário o estabelecimento de rotinas relacionadas às medidas de precaução imediatas, bem como as orientações e a disponibilidade da quimioprofilaxia em casos de acidentes com material biológico de pacientes soropositivos para o HIV ou desconhecidos.

Entretanto, pouco se sabe sobre o nível de conhecimento dos profissionais de saúde sobre o assunto, bem como o grau de adesão às normas de biossegurança. Em razão do potencial desconhecimento dessa realidade nas instituições de saúde brasileiras, faz-se necessário estabelecer novas políticas de saúde e segurança para aqueles que cuidam da saúde da população.

Outro fator importante está relacionado ao termo biossegurança que tem assumido, a partir da Lei $n$. 8.975, de 5 de janeiro de 1995, 5 que criou a Comissão Técnica Nacional de Biossegurança (CTNBio), uma dimensão ampla, que extrapola a área da saúde e do trabalho, sendo empregada quando há referência ao meio ambiente e à biotecnologia 6 . Todavia, não se percebe o mesmo empenho, principalmente governamental, de se discutir as questões relacionadas à biossegurança no ambiente hospitalar e à saúde dos trabalhadores envolvidos.

Considerando que este estudo também trata do conhecimento dos profissionais de saúde e a adesão destes às medidas de biossegurança frente ao potencial risco de transmissão do HIV, o conceito de biossegurança adotado será o instituído pela Comissão de Biossegurança da Fundação Oswaldo Cruz, o qual é definido como "o conjunto de medidas voltadas para a prevenção, a minimização ou a eliminação de riscos inerentes às atividades de pesquisa, produção, ensino, desenvolvimento tecnológico e prestação de serviços, que podem comprometer a saúde do homem, dos animais, do meio ambiente ou a qualidade dos trabalhos desenvolvi- dos. Estas medidas são classificadas em quatro grupos: medidas administrativas, técnicas, educacionais e médicas" 7 (p. 13).

Face ao exposto, o objetivo deste estudo é identificar os fatores que interferem no acidente de trabalho envolvendo material biológico em profissionais de saúde.

\section{Métodos}

Trata-se de estudo epidemiológico, descritivo, do tipo inquérito transversal, realizado em seis hospitais públicos do Distrito Federal, Brasil, em 2002 e 2003.

A seleção da amostra das unidades hospitalares foi feita por método aleatório estratificado, definido segundo o porte dos hospitais. Foram estabelecidos três estratos: o primeiro, composto por um hospital de grande porte $(>300$ leitos). O segundo, por dois hospitais de médio porte ( $>100$ e $<300$ leitos) e, o terceiro, por três hospitais de pequeno porte $(<100$ leitos). Dentre as unidades hospitalares que compõem este estudo, quatro são da Secretaria de Estado de Saúde do Distrito Federal (SES-DF) e duas são organizações militares.

Em cada unidade selecionada foram entrevistados o mínimo de $15,0 \%$ dos profissionais de saúde, perfazendo um total de 570 profissionais, pertencentes às seguintes categorias: cirurgião-dentista; enfermeiro; farmacêuticobioquímico; médico; técnico de laboratório de análises clínicas; técnico de enfermagem; auxiliar de enfermagem; atendente de enfermagem e auxiliar técnico de laboratório. Procurou-se contemplar todas as categorias e todos os turnos de trabalho.

Para a coleta de dados foi utilizada técnica de entrevista, por meio de um instrumento do tipo roteiro semi-estruturado, o qual abordou aspectos como: conhecimento sobre biossegurança, uso de equipamentos de proteção individual (EPI), ocorrência de acidente de trabalho, reencape de agulha, risco de transmissão ocupacional, aceitação da quimioprofilaxia e realização de teste sorológico anti-HIV.

O instrumento foi validado por meio de préteste e aplicado individualmente por uma equipe multidisciplinar previamente treinada.

$\mathrm{O}$ projeto foi submetido à análise dos $\mathrm{Co}$ mitês de Ética em Pesquisa em Seres Humanos (CEP) da Faculdade de Ciências da Saúde, Universidade de Brasília (UnB) e da SES-DF, sendo aprovado em ambos.

Os dados foram armazenados no Access e posteriormente analisados por meio do programa SPSS 10.0. 
A análise foi realizada a partir dos dados do conjunto de profissionais de saúde, em relação à ocorrência de acidente de trabalho, por meio das seguintes taxas padronizadas:

- Coeficiente de acidentabilidade (C. A.)

C. A. $=\frac{\text { Total de acidentados }}{\text { Total de avaliados }} \times 100$

- Coeficiente de aceitação (C. Ac.)

Total de pessoas que

C. Ac. $=\frac{\text { aceitariam a quimioprofilaxia }}{\text { Total de profissionais avaliados }} \times 100$

$\mathrm{Na}$ análise estatística foram utilizados os seguintes testes:

- Teste Exato de Fisher: análise univariada para verificar o grau de associação entre a ocorrência de acidentes do trabalho e o conhecimento dos profissionais de saúde sobre biossegurança, a definição de biossegurança, o risco de transmissão do HIV em caso de acidente com material perfurocortante, o uso e a aceitação da quimioprofilaxia, o conhecimento dos profissionais sobre as precauções universais, o treinamento em biossegurança e a realização de teste sorológico anti-HIV, com nível de significância $(\mathrm{p}<0,05)$.

- Teste Qui-Quadrado: para verificar a diferença estatística entre a freqüência em que os profissionais de saúde relataram ter o conhecimento sobre as normas de biossegurança e a disponibilidade das mesmas, com nível de significância $(\mathrm{p}<0,05)$.

\section{Resultados}

Os seis hospitais possuíam um total de 6.179 trabalhadores, dos quais 57,0\% (3.466) são profissionais de saúde. Do conjunto desses profissionais foram avaliados em média $16,4 \%$, totalizando 570 profissionais de saúde.

Dentre os profissionais de saúde avaliados, $223(39,1 \%)$ referiram ter sofrido acidente de trabalho com material biológico.

Ao se avaliar a distribuição das categorias profissionais em relação ao sexo, observa-se uma predominância feminina em todas as categorias, totalizando $75,2 \%$ da amostra.

A idade dos profissionais de saúde variou entre 20 e 68 anos, apresentando uma média de 38,8 \pm 9,3 anos, e mediana de 32 anos. Observa-se que os profissionais de saúde são pessoas jovens, uma vez que $71,2 \%$ estão concentrados na faixa etária ampliada de 20 a 39 anos e mediana de 29 anos.
Em relação à distribuição do tempo de serviço, verifica-se que os profissionais de saúde apresentaram uma média de 10,3 $\pm 8,1$ anos.

$\mathrm{Na}$ avaliação da influência do porte do hospital e da categoria profissional no coeficiente de acidentabilidade de trabalho envolvendo material biológico, observou-se uma relação inversamente proporcional ao coeficiente de acidentabilidade. Foram registrados para grande, médio e pequeno porte, 32,9, 39,9 e 44,1, respectivamente.

Quanto à categoria profissional, aquelas cujos profissionais mais relataram acidentes com material biológico foram a de cirurgiãodentista $(64,3)$, médico $(47,8)$ e técnico de laboratório $(46,0)$, enquanto o menor relato observou-se na categoria dos farmacêuticos-bioquímicos $(17,6)$.

Analisando-se o coeficiente de acidentabilidade de trabalho segundo o sexo dos profissionais de saúde, verificou-se uma ligeira predominância no sexo masculino.

Esse mesmo indicador, analisado de acordo com o sexo e a categoria profissional (Figura 1), mostrou que entre os profissionais do sexo masculino, os maiores coeficientes correspondem à categoria de atendente de enfermagem $(100,0)$ e entre os técnicos de laboratório $(72,2)$. Entre as mulheres, as categorias que mais se acidentaram foram as de cirurgiã-dentista e médica, 72,2 e 50,8, respectivamente.

No conjunto dos profissionais de saúde houve pouca diferença entre as faixas etárias. Os maiores coeficientes foram observados nas faixas etárias de 30 a 39 anos e de 50 a 59, com 43,5 e 43,2, respectivamente.

$\mathrm{Na}$ análise do coeficiente de acidentabilidade de trabalho, segundo o tempo de serviço na atividade, identifica-se a faixa de 11 a 15 anos como a mais vulnerável, tanto no conjunto dos profissionais (54,8 acidentados em 100 profissionais) quanto individualmente, nos níveis médio $(57,1)$ e superior $(58,3)$.

$\mathrm{Na}$ análise da interferência do tempo de atividade e da categoria profissional no coeficiente de acidentabilidade, subdividiu-se o tempo de atividade em menor ou igual a 10 anos e maior de 10 anos e observou-se pouca diferença entre esses dois grupos. A categoria técnico de laboratório obteve maior coeficiente entre os profissionais com mais de 10 anos, enquanto que na categoria médica o coeficiente foi maior entre aqueles com menor tempo de serviço.

Constatou-se associação significativa entre a freqüência em que os profissionais de saúde que se acidentaram relataram ter conhecimento sobre as normas de biossegurança $\left(\chi^{2}=178,985\right.$; 
Coeficiente de acidentabilidade de trabalho segundo a categoria profissional e o sexo do acidentado.

Distrito Federal, Brasil, 2002/2003.

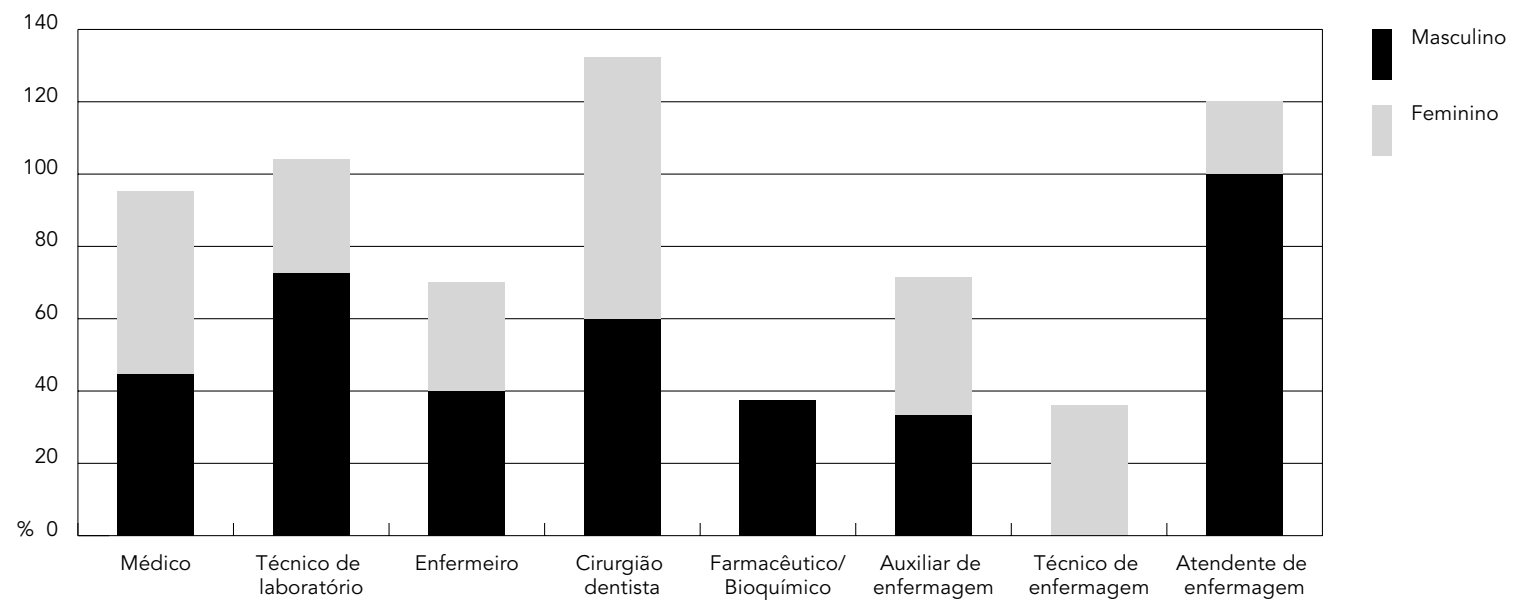

$\mathrm{df}=2 ; \mathrm{p}=0,000)$ e a disponibilidade das mesmas na unidade de trabalho $\left(\chi^{2}=231,217\right.$; $\mathrm{df}=$ $3 ; \mathrm{p}=0,000)$.

Não houve influência do fato de os profissionais de saúde afirmarem ter conhecimento do conceito de biossegurança no coeficiente de acidentabilidade de trabalho, uma vez que esse indicador foi maior entre aqueles que conheciam o conceito $(50,0)$ do que entre os que declaram não o conhecer $(37,5)$.

$\mathrm{O}$ treinamento recebido pelos profissionais de saúde, com conteúdo sobre biossegurança, nos últimos dois anos não diminuiu o coeficiente de acidentabilidade de trabalho envolvendo material biológico. Os dados apontam um coeficiente mais elevado para aqueles que referem ter recebido treinamento $(44,5)$ do que para os que não receberam $(37,3)$.

O fato de os profissionais de saúde terem ou não conhecimento do risco de transmissão ocupacional do HIV não interferiu significativamente no coeficiente de acidentabilidade de trabalho, apresentando coeficiente maior entre aqueles que conheciam o risco $(41,2)$.

Quanto ao uso de equipamentos de proteção individual, a influência do conhecimento dessas medidas e a adesão dos profissionais à utilização das mesmas no coeficiente de acidente de trabalho mostraram haver pouca ou nenhuma relação significativa entre essas variáveis.

O índice de reencape de agulha e o coeficiente de acidentabilidade segundo o sexo, mos- traram que os profissionais do sexo masculino reencapam mais agulhas do que os profissionais do sexo feminino. Observou-se um maior coeficiente de acidentabilidade entre aqueles que sabem que não se deve reencapar agulha.

Considerando o conjunto de profissionais que sofreram acidentes de trabalho, segundo o tipo e a categoria profissional, observa-se que $86,5 \%$ do total de acidentes envolveram exposição percutânea. Nesse tipo de acidente, destacam-se as categorias de farmacêutico-bioquímico, atendente de enfermagem, auxiliar de enfermagem e cirurgião-dentista como aquelas com o maior porcentual de acidentes, totalizando $100,0 \%, 100,0 \%, 97,1 \%$ e $94,4 \%$, respectivamente. Por outro lado, as categorias que apresentam maior porcentual de acidentes por contato cutâneo-mucosa com fluidos potencialmente contaminados são as de enfermeiro $(23,5 \%)$ e de técnico de laboratório (13,0\%) (Figura 2).

A distribuição dos profissionais de saúde acidentados com material biológico, em relação à aceitação de quimioprofilaxia, em casos de acidentes com indicação para a mesma, mostrou que, dos 223 acidentados, $87,4 \%$ aceitariam a quimioprofilaxia, e destes últimos 30,0\% efetivamente a realizaram (Tabela 1 ).

Quanto à realização da sorologia anti-HIV, do total de acidentados, $80,3 \%$ relataram ter realizado o teste (Tabela 1 ).

Visando a conhecer o nível de aceitação da quimioprofilaxia por parte dos profissionais de 
Percentual de acidentados segundo o tipo de acidente com material biológico.

Distrito Federal, Brasil, 2002/2003.

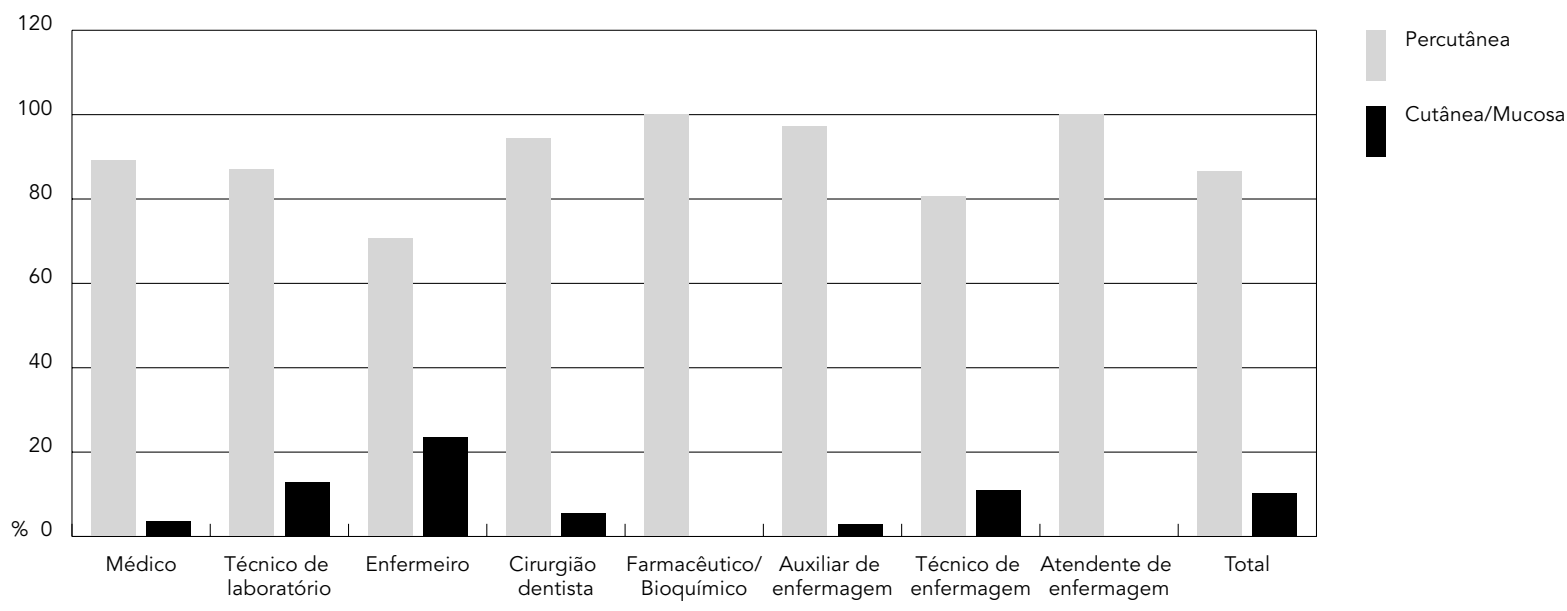

Tabela 1

Percentual de acidentados segundo a aceitação e o uso de quimioprofilaxia (QP), teste anti-HIV e porte do hospital. Distrito Federal, Brasil, 2002/2003.

\begin{tabular}{|c|c|c|c|c|c|c|c|c|c|c|}
\hline \multirow[t]{2}{*}{$\begin{array}{l}\text { Estrato/Unidade } \\
\text { hospitalar* }\end{array}$} & \multicolumn{2}{|c|}{ Aceitação QP } & \multicolumn{2}{|c|}{ Uso de QP } & \multicolumn{2}{|c|}{$\begin{array}{l}\text { Realização do } \\
\text { teste anti-HIV }\end{array}$} & \multicolumn{2}{|c|}{$\begin{array}{c}\text { Total de } \\
\text { acidentados }\end{array}$} & \multicolumn{2}{|c|}{$\begin{array}{c}\text { Total de } \\
\text { profissionais }\end{array}$} \\
\hline & $\mathrm{n}$ & $\% * \star$ & $\mathrm{n}$ & 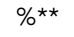 & $n$ & $\%$ \%* & $\mathrm{n}$ & 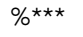 & $n$ & $\%$ \\
\hline \multicolumn{11}{|l|}{ Grande porte } \\
\hline A & 47 & 88,7 & 17 & 32,1 & 48 & 90,6 & 53 & 32,9 & 161 & 28,2 \\
\hline Total & 47 & 88,7 & 17 & 32,1 & 48 & 90,6 & 53 & 32,9 & 161 & 28,2 \\
\hline \multicolumn{11}{|l|}{ Médio porte } \\
\hline B & 54 & 91,5 & 21 & 35,6 & 44 & 74,8 & 59 & 46,8 & 126 & 22,1 \\
\hline C & 38 & 95,0 & 13 & 32,5 & 32 & 80,0 & 40 & 32,8 & 122 & 21,4 \\
\hline Total & 92 & 92,9 & 34 & 34,3 & 76 & 76,7 & 99 & 39,9 & 248 & 43,5 \\
\hline \multicolumn{11}{|l|}{ Pequeno porte } \\
\hline $\mathrm{D}$ & 17 & 77,3 & 6 & 27,3 & 19 & 86,4 & 22 & 43,1 & 51 & 8,9 \\
\hline$E$ & 27 & 90,0 & 7 & 23,3 & 23 & 76,7 & 30 & 37,5 & 80 & 14,0 \\
\hline $\mathrm{F}$ & 12 & 70,6 & 3 & 17,6 & 13 & 76,5 & 17 & 56,7 & 30 & 5,3 \\
\hline Total & 56 & 78,9 & 16 & 22,5 & 55 & 77,5 & 71 & 44,1 & 161 & 28,2 \\
\hline Total geral & 195 & 87,4 & 67 & 30,0 & 179 & 80,3 & 223 & 39,1 & 570 & 100,0 \\
\hline
\end{tabular}

* Unidades hospitalares: A, B, C, D, E, F.

** Percentual calculado em relação ao total de acidentados.

*** Coeficiente de acidentabilidade. 
saúde acidentados, frente ao risco de transmissão do HIV, foram estabelecidas algumas situações ligadas ao acidente que interfeririam positiva ou negativamente nessa aceitação (Tabela 2). Dentre estas, as situações em que o paciente-fonte apresentava carga viral intensa e/ou sorologia positiva prévia foram aquelas que mais contribuíram para a decisão do profissional em aceitar a quimioprofilaxia, totalizando $94,6 \%$ e $94,2 \%$, respectivamente, seguida por paciente-fonte fase inicial $(91,9 \%)$ e profundidade e extensão da superfície de contato $(91,5 \%)$ (Tabela 2).

O coeficiente de aceitação geral dos profissionais acidentados em relação à quimioprofilaxia foi de 87,4. Na análise específica de cada situação do acidente quanto à aceitação da quimioprofilaxia, os maiores coeficientes encontrados foram para a sorologia positiva do paciente-fonte $(99,6)$ e a carga viral intensa $(99,0)$ (Tabela 2). Ao se verificar o nível de significância estatística apresentado pelas variáveis estudadas em relação à ocorrência de acidentes do trabalho - análise univariada - Teste Exato de Fisher, observou-se que não houve diferença estatisticamente significante para as variáveis: conhecimento das precauções universais, treinamento em biossegurança, reencape de agulha e teste sorológico anti-HIV (Tabela 3).

Entretanto, para as variáveis: conhecimento sobre biossegurança, definição sobre biossegurança, risco de transmissão, uso de quimio- profilaxia e aceitação da quimioprofilaxia, verificou-se que houve diferença estatisticamente significante (Tabela 3).

\section{Discussão}

A principal causa de acidentes de trabalho em profissionais de saúde está relacionada ao uso de material perfurocortante 8 . Neste estudo, a maioria dos profissionais de saúde relatou ter sofrido acidente com esse tipo de material.

O número de acidentes envolvendo material biológico pode ser reduzido se as normas de biossegurança forem implementadas no ambiente de trabalho, conforme demonstrado no estudo de Beekmann et al. 9 , realizado no Centro Clínico do Instituto Nacional de Saúde dos Estados Unidos, em Maryland. Os acidentes relacionados a comportamentos considerados de risco, como reencapar agulhas, diminuíram de 16,0\% para 10,0\%, redução estatisticamente significativa, o que comprova a eficiência dessa recomendação.

Quanto ao coeficiente de acidentabilidade por categoria, neste estudo o cirurgião-dentista ocupou o primeiro lugar, o que pode ser explicado pela prática diária com materiais perfurocortantes. Estudo realizado também em Maryland, entre esses profissionais, constatou um aumento no uso de barreiras. Entretanto, destacou altas taxas de reencape de agulhas,

Coeficiente de aceitação de quimioprofilaxia e distribuição dos profissionais de saúde, segundo a situação em que potencialmente aceitariam fazer uso da mesma. Distrito Federal, Brasil, 2002/2003.

\begin{tabular}{|c|c|c|c|c|c|c|c|}
\hline \multirow[t]{3}{*}{ Situação do acidente } & \multirow{3}{*}{$\begin{array}{l}\text { Coeficiente } \\
\text { de aceitação }\end{array}$} & \multicolumn{4}{|c|}{ Aceitação da quimioprofilaxia } & \multirow{2}{*}{\multicolumn{2}{|c|}{ Total }} \\
\hline & & \multicolumn{2}{|c|}{ Sim } & \multicolumn{2}{|c|}{ Não } & & \\
\hline & & $\mathrm{n}$ & $\%$ & $\mathrm{n}$ & $\%$ & $\mathrm{n}$ & $\%$ \\
\hline Acidentes de pequena magnitude & 64,4 & 124 & 55,6 & 99 & 44,4 & 223 & 100,0 \\
\hline $\begin{array}{l}\text { Profundidade e extensão da superfície } \\
\text { de contato no acidente }\end{array}$ & 92,8 & 204 & 91,5 & 19 & 8,5 & 223 & 100,0 \\
\hline Pequena quantidade de material inoculado & 83,8 & 171 & 76,7 & 52 & 23,3 & 223 & 100,0 \\
\hline $\begin{array}{l}\text { Impossibilidade do teste sorológico } \\
\text { do contaminante }\end{array}$ & 91,3 & 196 & 87,9 & 27 & 12,1 & 223 & 100,0 \\
\hline $\begin{array}{l}\text { Demora para a obtenção do resultado } \\
\text { do paciente-fonte }\end{array}$ & 91,8 & 183 & 82,1 & 40 & 17,9 & 223 & 100,0 \\
\hline Paciente-fonte em fase inicial da doença & 97,1 & 205 & 91,9 & 18 & 8,1 & 223 & 100,0 \\
\hline Sorologia positiva do paciente-fonte & 99,6 & 210 & 94,2 & 13 & 5,8 & 223 & 100,0 \\
\hline Sorologia negativa do paciente-fonte & 49,4 & 82 & 36,8 & 141 & 63,2 & 223 & 100,0 \\
\hline $\begin{array}{l}\text { Carga viral intensa do paciente-fonte } \\
\text { do acidente }\end{array}$ & 99,0 & 211 & 94,6 & 12 & 5,4 & 223 & 100,0 \\
\hline oeficiente de aceitação = & aceitariam a c & imiop & ofilaxia & & & & \\
\hline
\end{tabular}


Nível de significância estatística apresentado pelas variáveis estudadas em relação à ocorrência de acidentes de trabalho.

\begin{tabular}{ll}
\hline $\begin{array}{l}\text { Com significância estatística } \\
\mathbf{p}<0,05\end{array}$ & $\begin{array}{l}\text { Sem significância estatística } \\
\mathbf{p}>0,05\end{array}$ \\
\hline $\begin{array}{l}\text { Conhecimento sobre biossegurança }(0,05) \\
\text { Definição sobre biossegurança }(0,04)\end{array}$ & $\begin{array}{l}\text { Conhecimento das precauções universais }(0,68) \\
\text { Treinamento em biossegurança }(0,14)\end{array}$ \\
Usisco de transmissão $(0,00)$ & Reencape de agulha $(0,62)$ \\
Aceitação da quimioprofilaxia $(0,00)$ & Teste sorológico anti-HIV $(0,33)$ \\
\hline
\end{tabular}

Análise univariada - Teste Exato de Fisher.

problema de difícil solução, uma vez que, nessa categoria, a natureza específica do procedimento "anestesia" exige a repetição desse ato durante um mesmo atendimento 10.

No Brasil, onde não existem muitas pesquisas direcionadas exclusivamente à categoria de cirurgião-dentista, os estudos apontam o atendente de enfermagem, seguido do auxiliar de enfermagem, como os profissionais que mais se acidentam. A justificativa apresentada é a de que os profissionais com pouca ou nenhuma qualificação profissional estão mais expostos aos riscos de acidentes 11,12,13. Paradoxalmente, neste estudo, essas categorias obtiveram o quinto e quarto maiores coeficientes de acidentabilidade, respectivamente.

A distribuição dos profissionais que se acidentaram segundo o sexo é diferenciada em vários estudos, embora se perceba um predomínio do sexo feminino $14,15,16$. Isso pode ser explicado pelo fato desses estudos terem sido realizados na equipe de enfermagem, considerada predominantemente feminina 17 .

Em contrapartida, Brandi et al. 18 observaram a tendência de o grupo masculino acidentar-se mais que o feminino na realização das mesmas tarefas. Entre os profissionais deste estudo, a diferença entre os dois sexos foi quase insignificante. Entretanto, o fato do profissional do sexo masculino ter se acidentado mais está relacionado à prática do reencape de agulhas ser maior entre esses profissionais, estando mais expostos ao risco.

A incorporação da prática de não reencapar agulhas pelos profissionais de saúde requer o suprimento adequado de recipientes próprios para descarte em todas as unidades hospitalares. Saghafi et al. 19, também sugeriram tornar mais acessíveis os recipientes próprios para descarte, bem como a rotina de descartar esses recipientes antes da superlotação. Esses estudos ressaltam a importância de se fazer um diagnóstico das condições de risco de acidentes com agulhas, a fim de buscar soluções fundamentadas na realidade de cada instituição hospitalar.

Com relação à faixa etária, este estudo encontrou na população compreendida entre 30 e 39 anos o maior coeficiente de acidentabilidade, dado que corrobora os resultados de Brandi et al. 18, que também avaliaram se os materiais perfurocortantes estavam infectados com o HIV. Essa avaliação não foi realizada neste estudo, mas o material perfurocortante representou a principal causa de acidente.

O tempo de serviço não influenciou no coeficiente de acidentabilidade, entretanto, os dados mostraram que a categoria médica apresentou um maior coeficiente de acidentabilidade dentre aqueles que possuíam menor tempo de serviço, provavelmente, em decorrência da inexperiência.

Dentre os profissionais entrevistados, os que afirmaram conhecer todas as normas de biossegurança foram os que mais se acidentaram. Isso se deve, em parte, por considerarem ter adquirido um conhecimento que, na prática, não acontece, ou por estarem mais expostos aos riscos de transmissão do que a parcela que relatou desconhecer ou ter um conhecimento parcial dessas normas. Isso pôde ser observado especificamente na categoria farmacêutico-bioquímico, que apresentou o menor coeficiente de acidentabilidade, uma vez que o risco de exposição desses profissionais é menor do que o dos demais.

$\mathrm{O}$ treinamento recebido pelos profissionais estudados não interferiu no coeficiente de acidentabilidade, fato que deve ser melhor explorado, pois não apareceu neste estudo que esse treinamento tenha de fato resultado em uma melhoria na capacitação dos profissionais quanto às normas de precaução universal. 
A relação entre o conhecimento e a adesão dos profissionais de saúde ao uso de barreiras de proteção não foi significativa. Demonstrouse que eles têm o conhecimento, mas não aderem às medidas e possuem uma percepção fraca de risco, pois fazem uso de barreiras apenas mediante o diagnóstico de soropositividade para HIV. Este é um dos aspectos mais preocupantes, uma vez que esta falsa segurança aumenta significativamente o risco da transmissão do HIV.

Particularmente para os profissionais de saúde, o uso de barreiras de proteção deve ser conduta priorizada, diferentemente do que é recomendado pela Portaria n. 3.214 do Ministério do Trabalho e Emprego para os agentes insalubres químicos e físicos 20 . Nos casos dos agentes químicos e físicos, os EPIs devem ser adotados tanto quanto todas as outras possibilidades (equipamentos de proteção coletiva, controle da fonte). No caso dos agentes biológicos, como em grande parte das situações é impossível ou inviável o controle da fonte ou do ambiente como um todo, as barreiras de proteção, representadas nesse caso pelos EPIs, devem estar presentes em todas as situações que ofereçam risco, mesmo que potencial.

A eficiência dessas barreiras foi demonstrada no estudo de Bennet \& Howard 21 e Mast et al. 22, que comprovaram que as luvas funcionam como medidas de proteção no caso de acidentes com exposição da pele das mãos a sangue e fluidos corporais. No caso de acidentes perfurocortantes foi demonstrado que uma única luva pode reduzir o volume de sangue injetado por agulhas maciças de sutura, em 70,0\%. No caso de agulhas ocas, a luva pode reduzir de $35,0 \%$ a $50,0 \%$ a inoculação do sangue, uma vez que uma porção deste permanece na parte interna da agulha 23. Mesmo oferecendo redução menor que com agulhas maciças, sem dúvida a utilização de luvas configura uma barreira auxiliar para a prevenção de acidentes perfurocortantes.

Conforme as normas pós-acidente, os profissionais devem ser encaminhados para coleta de sorologia anti-HIV, hepatites B e C 18. Entretanto, questionados sobre essa coleta, somente $54,3 \%$ referiram ter realizado teste anti-HIV, dado que não foi corroborado neste estudo, em que o percentual de profissionais que afirmaram ter realizado esse teste foi bem maior, o que demonstra que eles aderiram mais a alguns dos procedimentos recomendados.

Quanto à aceitação e ao uso da quimioprofilaxia pelos profissionais estudados, no período pós-acidente, uma grande maioria afirmou que aceitaria fazer uso da medicação, mas, na prática, esse dado não foi tão expressivo, provavelmente, em decorrência da ausência de indicação de uso da quimioprofilaxia, devido ao tipo de acidente, ou pelo fato de o profissional acidentado ter optado por não fazer uso da medicação em função dos efeitos colaterais. Pode-se questionar também a falta da orientação correta dos serviços responsáveis, nas unidades hospitalares, pelo controle dos acidentes de trabalho.

De modo geral, observa-se que a ocorrência de acidentes de trabalho envolvendo material biológico potencialmente infectado pelo HIV foi significativa, sendo de primordial relevância o desenvolvimento de medidas técnicas e administrativas para a minimização desse problema.

Vale ressaltar que a relação conhecimento das normas de biossegurança e treinamento demonstraram que os treinamentos desenvolvidos devem ser reavaliados. Esse dado pode ser alarmante num primeiro momento, já que atualmente muito se confia e investe em treinamento enquanto ferramenta de capacitação profissional. Deve-se no entanto, observar o tipo de treinamento, sua qualidade, sua adequação ao tipo de ambiente e de categoria profissional que se pretende atingir. Além de propor a implantação de um programa de educação continuada, que possa constantemente mobilizar os profissionais quanto às ações de proteção dos profissionais de saúde, principalmente as que dizem respeito à prevenção de acidentes envolvendo material biológico potencialmente infectante.

Sendo assim, este estudo sugere a implementação de medidas de biossegurança em hospitais, que são fundamentais para a proteção dos profissionais de saúde. Tais medidas abrangem tanto questões de ordem administrativa, de organização do trabalho, como relacionadas à educação continuada, e ao controle de qualidade e prevenção de acidentes.

\section{Conclusões}

Os dados apresentados permitem concluir que o coeficiente de acidentabilidade foi inversamente proporcional ao porte do hospital; os profissionais de saúde do sexo masculino acidentaram-se mais do que os do sexo feminino; as categorias cirurgião-dentista, médico e técnico de laboratório foram as que mais se acidentaram; a realização de treinamento com conteúdos sobre biossegurança não interferiram positivamente na diminuição de acidentes; os profissionais de saúde com maior tem- 
po de serviço se acidentaram mais, a exceção dos médicos que apresentaram uma relação inversa; o coeficiente de acidentabilidade foi maior entre os profissionais de saúde que afirmaram conhecer todas as normas; não houve relação positiva entre o conhecimento e a adesão quanto ao uso de EPI entre os profissionais de saúde.

Estes resultados apontam para a necessidade de uma reavaliação da estrutura e dos conteúdos dos treinamentos em serviços oferecidos aos profissionais de saúde no Distrito Federal.

\section{Resumo}

Foi estudada a ocorrência de acidente de trabalho em profissionais de saúde no período de 2002/2003 e a influência das medidas de biossegurança e aceitação de quimioprofilaxia frente ao risco de transmissão ocupacional do HIV. Avaliou-se 570 profissionais de saúde de seis hospitais públicos, selecionados aleatoriamente, do conjunto de hospitais do Distrito Federal, Brasil. Esses profissionais foram questionados quanto ao conhecimento sobre biossegurança, ocorrência de acidente de trabalho, aceitação da quimioprofilaxia e teste sorológico anti-HIV. Entre os profissionais avaliados, o coeficiente de acidentabilidade foi de 39, 1 e mostrou-se inversamente proporcional ao porte do hospital. Dentistas, médicos e técnicos de laboratório acidentaram-se mais, em contrapartida aos farmacêuticos e enfermeiros. As situações relacionadas ao acidente de trabalho com maior aceitação e adesão ao uso da quimioprofilaxia foram sorologia positiva e carga viral intensa do paciente-fonte (99,6-99,0\%), em contraposição à sorologia negativa do paciente-fonte e acidente de pequena proporção (36,8-55,6\%). O conhecimento dos profissionais de saúde sobre o conceito e as normas de biossegurança, a disponibilidade destas na unidade de trabalho e a realização de treinamento em biossegurança não influenciaram positivamente no coeficiente de acidentabilidade de trabalho.

Biossegurança; Síndrome de Imunodeficiência Adquirida; Pessoal de Saúde; Acidentes de Trabalho

\section{Colaboradores}

R. B. Caixeta e A. Barbosa-Branco participaram em conjunto de todas as etapas de elaboração do artigo.

\section{Agradecimentos}

Aos acadêmicos de medicina Gustavo Vasconcelos Carvalho e Paulo José Tonello Ferreira pela colaboração na coleta de dados, ao Ministério da Saúde e à UNESCO (CFA n. 645-2) pelo financiamento desta pesquisa. 


\section{Referências}

1. Oskenhendler E, Harzic M, Leroux JM, Rabian C, Clauvel JP. HIV infection with seroconversion after a superficial needlestick injury to the finger. $\mathrm{N}$ Engl J Med 1986; 315:582.

2. Henderson DK, Saah AJ, Zak BJ, Kaslow RA, Lane HC, Folks T, et al. Risk of nosocomial infection with human T-cell lymphotropic virus type III/ lymphadenopathy associated virus in a large cohort of intensively exposed health-care workers. Ann Intern Med 1986; 104:644-7.

3. Coordenação Nacional de DST e AIDS. Controle de infecções e a prática odontológica em tempos de AIDS: manual de condutas. Brasília: Secretaria de Políticas de Saúde, Ministério da Saúde; 2000.

4. Oliveira SG. Proteção jurídica à saúde do trabalhador. São Paulo: LTR; 1996.

5. Brasil. Lei n. 8.974. Dispõe sobre a criação da Comissão Técnica Nacional de Biossegurança, e dá outras providências. Diário Oficial da União 1995; 6 jan.

6. Sant'Ana A. Biossegurança no Brasil: a necessidade de uma política consistente. In: Teixeira P, Valle S, organizadores. Biossegurança: uma abordagem multidisciplinar: Rio de Janeiro: Editora Fiocruz; 1996. p. 27-40.

7. Teixeira P, Valle S, organizadores. Biossegurança: uma abordagem multidisciplinar. Rio de Janeiro: Editora Fiocruz; 1998.

8. Sarquis LMM. Acidentes de trabalho com instrumentos perfurocortantes: ocorrência entre os trabalhadores de enfermagem [Dissertação de Mestrado]. São Paulo: Universidade de São Paulo; 1999.

9. Beekman SE, Vlahov D, Koziol DE, McShalley ED, Schmitt JM, Henderson DK. Temporal association between implementation of universal precautions and a sustained, progressive decrease in percutaneous exposures to blood. Clin Infect Dis 1994; 18:562-9.

10. Gershon RRM, Karkashian C, Vlahov D, Grimes M, Spannhake E. Correlates of infection control practices in dentistry. Am J Infect Control 1998; 26:29-34.

11. Oliveira MG, Makaron PE, Mororne LC. Aspectos epidemiológicos dos acidentes de trabalho em um hospital geral. Rev Bras Saúde Ocup 1982; 10:26-30.
12. Faria MP, Silva AM. Análise de acidentes do trabalho ocorridos durante parte do ano de 1983, na grande Belo Horizonte. Rev Bras Saúde Ocup 1983; 11:26-32.

13. Silva VEF. Estudo sobre acidentes de trabalho ocorridos com trabalhadores de enfermagem de um hospital de ensino [Dissertação de Mestrado]. São Paulo: Universidade de São Paulo; 1983.

14. Souza M, Vianna LAC. Incidência de acidentes de trabalho relacionada com a não utilização das precauções universais. Rev Bras Enfermagem 1993; 46:234-44.

15. Machado AA, Costa JC, Gir E, Moriya TM, Figueiredo JFC. Riscos de infecção pelo vírus da imunodeficiência humana (HIV) em profissionais da saúde. Rev Saúde Pública 1992; 26:54-6.

16. Devries B, Cossart YE. Neddlestick injury in medical students. Med J Aust 1994; 160:398-400.

17. Douglas JL. Contribuição para a caracterização da enfermagem que atua na assistência da saúde do trabalhador na América Latina [Dissertação de Mestrado]. São Paulo: Universidade de São Paulo; 1991.

18. Brandi S, Benatti MCC, Alexandre NMC. Ocorrência de acidente de trabalho por material perfurocortante entre trabalhadores de enfermagem de um hospital universitário da Cidade de Campinas, Estado de São Paulo. Rev Esc Enfermagem USP 1998; 32:124-33.

19. Saghafi L, Raselli P, Francillon C, Francioli P. Exposure to blood during various procedures: results of two surveys before and after the implementations of universal precaution. Am J Infect Control 1992; 20:53-7.

20. Ministério do Trabalho. Segurança e medicina do trabalho. São Paulo: Editora Atlas; 1995.

21. Bennet NT, Howard RJ. Quantity of blood inoculated in a needlestick injury from suture needles. J Am Coll Surg 1994; 178:107.

22. Mast ST, Woolwine JD, Gerberding JL. Efficacy of gloves in reducing blood volumes transferred during simulated needlestick injury. J Infect Dis 1993; 168:1589.

23. Rose DA. Usage patterns and perforation rates for 6,396 gloves from intra-operative procedures at San Francisco General Hospital. Infect Control Hosp Epidemiol 1994; 15:349.

Recebido em 17/Dez/2003

Versão final reapresentada em $03 /$ Nov/2004 Aprovado em 09/Nov/2004 